\title{
Purification and Partial Sequencing of the Nuclear Autoantigen RA33 Shows That It Is Indistinguishable from the A2 Protein of the Heterogeneous Nuclear Ribonucleoprotein Complex
}

\author{
Günter Steiner, * Klaus Hartmuth, ${ }^{\star}$ Karl Skriner, * Ingrid Maurer-Fogy, ${ }^{*}$ Alexandra Sinski, * Eva Thalmann, \\ Wolfgang Hassfeld," Andrea Barta, ${ }^{*}$ and Josef S. Smolen ${ }^{\star \|}$ \\ ${ }^{*}$ Ludwig Boltzmann Institute for Rheumatology and Balneology, A-1130 Vienna; ${ }^{\ddagger}$ Institute of Biochemistry, University of Vienna, A- \\ 1090 Vienna; ${ }^{\S}$ Ernst Boehringer Institute, A-1120 Vienna; and "2nd Department of Medicine, Lainz Hospital, A-1130 Vienna, Austria
}

\begin{abstract}
RA33 is a nuclear autoantigen with an apparent molecular mass of $33 \mathrm{kD}$. Autoantibodies against RA33 are found in about $30 \%$ of sera from RA patients, but only occasionally in sera from patients with other connective tissue diseases. To characterize RA33, the antigen was purified from HeLa cell nuclear extracts to more than $90 \%$ homogeneity by affinity chromatography on heparin-Sepharose and by chromatofocusing. Sequence analysis of five tryptic peptides revealed that their sequences matched corresponding sequences of the A2 protein of the heterogeneous nuclear ribonucleoprotein ( $h n R N P)$ complex. Furthermore, RA33 was shown to be present in the 40S hnRNP complex and to behave indistinguishably from $A 2$ in binding to single stranded DNA. In summary, these data strongly indicate that RA33 and $A 2$ are the same protein, and thus identify on a molecular level a new autoantigen. (J. Clin. Invest. 1992.90:1061-1066.) Key words: rheumatoid arthritis • autoimmune diagnostics $\bullet$ antinuclear antibodies $\bullet$ RNA binding protein $\bullet$ mRNA processing
\end{abstract}

\section{Introduction}

$\mathrm{RA}$ is the most common autoimmune disease and affects $1-2 \%$ of the population. Despite many years of intensive research, the etiology of the disease is still poorly understood, and no definite cure is known (1). Sera from patients with RA are primarily characterized by the presence of rheumatoid factor, an autoantibody directed against the Fc portion of $\operatorname{IgG}(2)$. In addition, autoantibodies against components of the cell nucleus (antinuclear antibodies) and against EBV-related structures are frequently observed (3-5). However, neither rheumatoid factor nor any of the other autoantibodies have been found to be specific for RA. Recently, autoantibodies against a nuclear protein with an apparent molecular mass of $33 \mathrm{kD}$ have been described (6). These autoantibodies were detected in $35 \%$ of RA patients but apart from a few exceptions not in sera from patients suffering from other autoimmune or degen-

Portions of this paper have appeared in abstract form in FASEB (Fed. Am. Soc. Exp. Biol.) J. 1990. 4:A3259; and Clin. Rheumatol. 1990. 9:576.

Address correspondence to Günter Steiner, Ludwig Boltzmann Institut fur Rheumatologie und Balneologie, 2. Medizinische Abteilung, Krankenhaus Lainz, Wolkersbergenstrasse 1, A-1130-Vienna, Austria. Received for publication 10 February 1992.

J. Clin. Invest.

(C) The American Society for Clinical Investigation, Inc.

0021-9738/92/09/1061/06 \$2.00

Volume 90, September 1992, 1061-1066 erative rheumatic disorders. Therefore, the antigen was termed RA33; this was the first description of a nuclear antigen apparently specific for RA.

Disease specific immune responses to nuclear antigens have been found for various autoimmune diseases: anti-Sm and anti-dsDNA in systemic lupus erythematosus (SLE), antitopoisomerase (Scl70) in scleroderma, or anti-tRNA synthetase in dermato/polymyositis are just a few examples. Other autoantibodies, such as anti-U1 small nuclear ribonucleoprotein (snRNP), ${ }^{1}$ anti-Ro/SS-A, anti-La/SS-B, or antihistone, are less specific but nevertheless, they do form valuable tools for the diagnosis of connective tissue diseases (for a review, see 7). In general, the target antigens are molecules conserved in evolution, many of which have the capacity to bind DNA or RNA, such as histones, topoisomerase, or snRNP particles involved in posttranscriptional processing of pre-mRNA (8).

In contrast to $\operatorname{snNPs}(9,10)$, components of the heterogeneous nuclear ribonucleoprotein ( $h n R N P$ ) complex have only rarely been described as target structures for human autoantibodies (11-13). So far, only the Al protein has been identified as autoantigen in a variety of autoimmune diseases $(14,15)$. HnRNPs are large nuclear structures composed of heterogeneous nuclear RNA and $\sim 30$ different proteins with molecular masses between 34 and $120 \mathrm{kD}$ (16). Six of these proteins (A1, A2, B1, B2, C1, C2) have been referred to as the hnRNP "core" proteins (17), and the sequences of their cDNAs have been recently elucidated (18-22). They belong to a group of nucleic acid binding proteins that contain an evolutionarily highly conserved RNA binding domain of $\sim 90$ amino acids, the so-called consensus sequence-type RNA binding domain (CS-RBD [23]). Little is known about the detailed structure and function of the hnRNP complex, but there is some evidence for a functional relationship to the snRNPs (24).

In this report, we describe the purification and partial sequencing of RA33. Furthermore, it is demonstrated that RA33 is present in the 40S hnRNP complex, and that it is indistinguishable from the $\mathrm{A} 2$ protein in affinity chromatography on single stranded DNA (ssDNA). Taken together, the data strongly suggest that RA33 and A2 are identical.

\section{Methods}

Protein purification. HeLa S3 cells or nuclei were obtained frozen from the Computer Cell Culture Center, (University of Mons, Belgium).

1. Abbreviations used in this paper: $\mathrm{CS}-\mathrm{RBD}$, consensus sequence-type RNA binding domain; hnRNP, heterogeneous nuclear ribonucleoprotein; MCTD, mixed connective tissue disease; snRNP, small nuclear ribonucleoprotein; ssDNA, single-stranded DNA. 
Isolation of nuclei and preparation of nuclear extracts was performed as described (6). Briefly, $10 \mathrm{~g}$ of nuclei were incubated for $30 \mathrm{~min}$ in 4 ml hypotonic buffer ( $10 \mathrm{mM}$ Hepes- $\mathrm{KOH}, 2.5 \mathrm{mM} \mathrm{MgCl} \mathrm{m}_{2}, 25 \%$ glycerol, $\mathrm{pH} \mathrm{7.9)}$ and subsequently extracted for $40 \mathrm{~min}$ by addition of an equal volume of the same buffer containing $0.88 \mathrm{M} \mathrm{NH}_{4} \mathrm{Cl}$. The slurry was centrifuged for $20 \mathrm{~min}$ at $20,000 \mathrm{~g}$, and the $\mathrm{NH}_{4} \mathrm{Cl}$ concentration of the supernatant was adjusted to $0.3 \mathrm{M}$ by diluting with $10 \mathrm{mM}$ Hepes$\mathrm{KOH}, \mathrm{pH}$ 7.9.

$40 \mathrm{ml}$ nuclear extract ( $\sim 200 \mathrm{mg}$ protein $)$ was applied to a $2.5 \times 20$ $\mathrm{cm}$ heparin-Sepharose CL-6B column (Pharmacia, Uppsala, Sweden) equilibrated with buffer A ( $20 \mathrm{mM}$ Hepes- $\mathrm{NaOH}, 0.3 \mathrm{M} \mathrm{NaCl}, \mathrm{pH}$ 7.9). The column was washed with 3 vol of buffer $A$, and bound protein was eluted with 3 vol of buffer $\mathrm{B}(20 \mathrm{mM}$ Hepes- $\mathrm{NaOH}, 1 \mathrm{M} \mathrm{NaCl}$, pH 7.9) followed by 3 vol of buffer C ( $20 \mathrm{mM}$ Hepes-NaOH, $1 \mathrm{M}$ $\mathrm{NaCl}, 6 \mathrm{M}$ urea, $\mathrm{pH}$ 7.9). Protein concentration of each fraction ( 10 $\mathrm{ml}$ ) was measured in a microplate reader at $620 \mathrm{~nm}$ using the Coomassie Protein Assay Reagent from Pierce Chemical Co. (Rockford, IL). Protein-rich fractions were analyzed for the presence of RA33 by immunoblotting, as described below. RA33 containing fractions were pooled ( $10 \mathrm{mg}$ total protein ), precipitated with $0.4 \mathrm{~g} / \mathrm{ml}$ ammonium sulphate, and redissolved in chromatofocusing starting buffer $(20 \mathrm{mM}$ Tris$\mathrm{CH}_{3} \mathrm{COOH}, 3 \mathrm{M}$ urea, $\mathrm{pH}$ 8.7). After dialyzing against the same buffer, proteins were further separated by chromatofocusing on a $15 \times 0.6 \mathrm{~cm}$ PBE 94 ion exchanger column (Pharmacia). A 1:8 diluted Polybuffer 96-acetic acid, $\mathrm{pH} \mathrm{6}$, containing $3 \mathrm{M}$ urea, was used as eluent (flow rate $8 \mathrm{ml} / \mathrm{h}$, fraction size $2 \mathrm{ml}$ ). Aliquots were precipitated with $10 \%$ TCA, redissolved in Laemmli sample buffer and investigated by immunoblotting. Fractions containing RA33 were pooled, precipitated with ammonium sulphate, and redissolved in either $20 \mathrm{mM}$ Tris- $\mathrm{HCl}, \mathrm{pH} 7.5$, containing $6 \mathrm{M}$ urea, or trypsin sequencing buffer (see below).

Protein sequencing. $20 \mu \mathrm{g}$ of purified RA33 were mixed with $0.1 \mathrm{ml}$

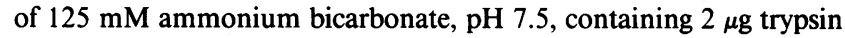
sequencing grade (Boehringer Mannheim $\mathrm{GmbH}$, Mannheim, Germany) and incubated for $6 \mathrm{~h}$ at $37^{\circ} \mathrm{C}$; an extra $2 \mu \mathrm{g}$ of trypsin was added and incubation was continued for another $16 \mathrm{~h}$. The resulting peptide fragments were separated by reversed phase HPLC on a $5 \mu \mathrm{m}$ C18 column (Deltapak; Waters Associates, Millipore Corp., Milford, MA) using a linear 0-70\% acetonitrile gradient in $0.1 \%$ trifluoroacetic acid. Five fractions corresponding to major peaks on the chromatogram were analyzed on a pulsed liquid phase sequenator (Type 477; Applied Biosystems, Inc., Foster City, CA).

ssDNA chromatography of hnRNP particles. HnRNP particles were extracted from intact nuclei as described by Beyer et al. (17). Briefly, nuclei were resuspended in STM (saline-Tris-magnesium) buffer ( 10 $\mathrm{mM}$ Tris- $\mathrm{HCl}, 2.5 \mathrm{mM} \mathrm{MgCl}, 0.1 \mathrm{M} \mathrm{NaCl}$ ) at $\mathrm{pH} 7.0$ and gently stirred for $30 \mathrm{~min}$ on ice. Nuclei were then pelleted at $700 \mathrm{~g}$ for $15 \mathrm{~min}$, resuspended in STM, pH 8, and stirred on ice for another $30 \mathrm{~min}$; this step was repeated twice. The $\mathrm{pH} 8$ extracts were used for ssDNA chromatography (16): $4.5 \mathrm{ml}$ of extract ( $10 \mathrm{mg}$ protein) was loaded onto a $10 \mathrm{ml}$ ssDNA agarose column (Bethesda Research Laboratories, Bethesda, MD) equilibrated with $50 \mathrm{mM}$ phosphate buffer, $\mathrm{pH} 7.4$, containing $0.1 \mathrm{M} \mathrm{NaCl}$. After extensive washing of the column with the same buffer, bound protein was eluted stepwise with $0.2 \mathrm{M} \mathrm{NaCl}, 0.3$ $\mathrm{M} \mathrm{NaCl}, 0.5 \mathrm{M} \mathrm{NaCl}$, and $2 \mathrm{M} \mathrm{NaCl}$, all in $50 \mathrm{mM}$ phosphate buffer, $\mathrm{pH}$ 7.4. Aliquots of protein containing fractions were precipitated with $10 \%$ TCA and analyzed by SDS-PAGE and immunoblotting.

Preparation of $40 S$ hnRNP complexes. HeLa cells (Wisconsin) were grown in monolayers $\left(175 \mathrm{~cm}^{2}\right)$ in DME supplemented with $10 \%$ FCS and glutamine. Nucleoplasm was prepared from isolated nuclei by sonication in STM buffer, pH 7.4, essentially as described (16), except that Triton X-100 was omitted during sonication and all subsequent steps. Volumes were adjusted so that six monolayers yielded $1 \mathrm{ml} \mathrm{nu}-$ cleoplasm. To prepare $40 \mathrm{~S}$ hnRNP complexes, $0.5 \mathrm{ml}$ of nucleoplasm were treated with 4 or $8 \mathrm{U} / \mathrm{ml}$ micrococcal nuclease (P-L Biochemicals, Inc., Milwaukee, WI) in the presence of $5 \mathrm{mM} \mathrm{CaCl}_{2}$ for $15 \mathrm{~min}$ at $30^{\circ} \mathrm{C}$. The nuclease reaction was stopped by addition of EGTA to 20 $\mathrm{mM}$. The nucleoplasm was then layered onto a $12-\mathrm{ml} 10-30 \%$ sucrose gradient in RSB-100 and centrifuged at $4^{\circ} \mathrm{C}$ for $14 \mathrm{~h}$ at $28,000 \mathrm{rpm}$ in a rotor (SW40; Beckman Instruments, Fullerton, CA). For reference. dissociated $70 \mathrm{~S} E$. coli ribosomes were run in parallel. Gradients were fractionated from bottom to top into $0.7 \mathrm{ml}$ fractions and their absorbence at $260 \mathrm{~nm}$ was determined. Protein was recovered from gradient fractions by TCA precipitation and was analyzed by immunoblotting with patient serum.

Gel electrophoresis and immunoblotting. Samples were usually analyzed on $12 \%$ SDS-polyacrylamide minigels $(8 \times 5 \mathrm{~cm} \times 0.75 \mathrm{~mm})$; in some experiments electrophoresis was performed on $20 \times 14 \mathrm{~cm} \times 1.5$ mm gels. Prestained protein markers from Bethesda Research Laboratories were used as mol wt references. Electrophoretic transfer to nitrocellulose (BAS 53; Schleicher und Schuell, Germany) was performed for $40 \mathrm{~min}$ at $250 \mathrm{~mA}$ for minigels, and for $2 \mathrm{~h}$ at $400 \mathrm{~mA}$ for large gels. For immunodetection, the nitrocellulose was blocked for $30 \mathrm{~min}$ with a solution of $3 \%$ nonfat dried milk in PBS, pH 7.4. Subsequently, the blots were incubated for 40 min with serum diluted 1:25 in the same buffer, washed $3 \times 5$ min with PBS containing $0.1 \%$ Triton X-100 (PBS-Triton) and incubated for $30 \mathrm{~min}$ with an alkaline phosphatase coupled anti-human IgG (Fc) 2nd antibody (Accurate Chemical \& Scientific Corp., Westbury, NY) diluted 1:2,500 in PBS-Triton, $3 \%$ nonfat dried milk. Finally, bound antibody was detected as described (6).

\section{Results}

Purification of $R A 33$. A HeLa nuclear extract containing $\sim 200 \mathrm{mg}$ protein was chromatographed on heparin-Sepharose as described in Methods. Immunoblot analysis showed that RA33 was detected exclusively in three fractions of the 1 $\mathrm{M} \mathrm{NaCl} / 6 \mathrm{M}$ urea eluate (Fig. 1); as these fractions contained about $10 \mathrm{mg}$ protein, RA33 was $\sim 20$-fold enriched. In addition to RA33, two proteins with estimated molecular masses measuring 36 and $37 \mathrm{kD}$ migrating slightly above RA33 were reactive with the serum used for immunodetection of RA33 (Fig. $2 B$, lane $H-S$ ). These proteins were not only reactive with the RA33 specific serum used in this experiment, but also with most anti-RA33 positive sera tested in addition (not shown) indicating an immunological relationship between these three antigens. The fractions were combined, precipitated with ammonium sulphate, redissolved and further separated by chromatofocusing. Approximately $80 \%$ of the total protein eluted in the flow-through of the PBE-94 column and in the initial fractions of the $\mathrm{pH}$ gradient (not shown). RA33 eluted in several fractions below $\mathrm{pH} 8$; the first two of these fractions con-

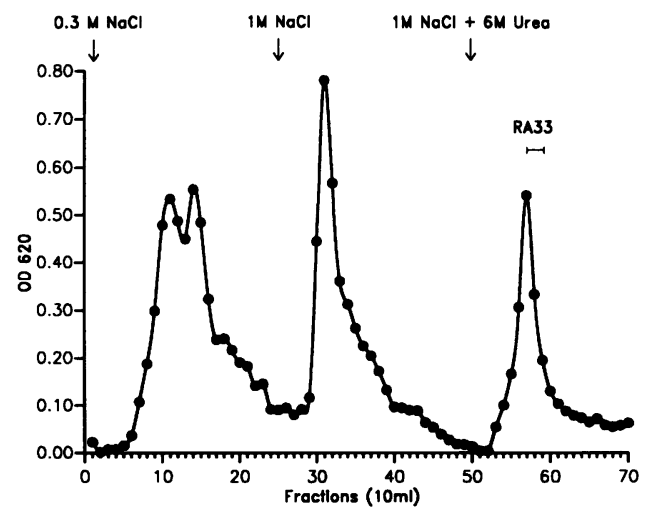

Figure 1. Heparin-Sepharose chromatography of a high salt HeLa cell nuclear extract. Buffer changes are indicated. Fractions were analyzed by immunoblotting (not shown). RA33 was contained in the peak and the two following fractions of the $1 \mathrm{M} \mathrm{NaCl} / 6 \mathrm{M}$ urea eluate as indicated. 


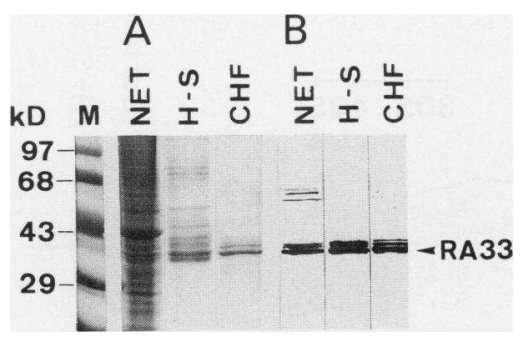

of the gel was stained with Coomassie blue $(A)$, the other half was blotted onto nitrocellulose and subsequently incubated with an RA33 specific serum $(B)$. The position of RA33 is indicated by an arrow. $M$, mol wt markers.

tained a $>90 \%$ pure preparation of RA33 as judged by Coomassie blue staining (Fig. $2 A$, lane $C H F$ ) and immunoblotting (Fig. $2 B$, lane $C H F$ ) of the purified proteins following SDSPAGE. The two immunoreactive proteins copurifying on heparin-Sepharose were not completely separated from RA33 by chromatofocusing, although a major portion of these two proteins eluted prior to RA33 at more basic $\mathrm{pH}$.

Sequence analysis of five tryptic peptides. Attempts to sequence the amino terminal part of purified RA33 failed, presumably because of a blocked NH terminus. The RA33 preparation was therefore digested with trypsin, and the resulting fragments were separated by reversed phase HPLC. Five peptides corresponding to major peaks of the HPLC chromatogram (not shown) were sequenced. Computer analysis revealed that their amino acid sequences were $100 \%$ identical with sequences of two proteins of the $40 \mathrm{~S}$ hnRNP complex: the core proteins $\mathrm{A} 2$ and $\mathrm{B} 1$ which have identical sequences except for a 12-amino acid insert near the $\mathrm{NH}_{2}$-terminus of $\mathrm{B} 1$ (21). Fig. 3 shows the sequence of $\mathrm{A} 2$ and the positions of the sequenced peptides, labeled $A-E$. Thus, peptides A (AsnTyr-Tyr-Glu-Gln-Trp-Gly-Lys) and B (Gly-Phe-Gly-Phe-ValThr-Phe-Asp-Asp-His-Asp-Pro-Val-Asp-Lys) corresponded to amino acids $27-34$ and $142-156$ of A2, respectively. These residues are located in the evolutionarily conserved amino terminal parts of the molecule (CS-RBD I and II), with peptide B containing seven amino acids of the most highly conserved octapeptide region, the RNP consensus sequence (Fig. 3 ). Peptides $C, D$ and $E(10,15$, and 20 amino acids, respectively) corresponded to A2 sequences situated outside the conserved region, and were therefore unique for this protein. In summary, the sequences of five peptides (68 amino acids corresponding to $20 \%$ of the A2 sequence) showed $100 \%$ identity with sequences of the A2/B1 protein of the hnRNP complex. Therefore, it was concluded that the protein sequenced was identical to $\mathrm{A} 2$ or $\mathrm{B} 1$.

$R A 33$ binds to SSDNA agarose and is contained in the $40 S$ $h n R N P$ particle. On the basis of the sequencing data alone, it was not possible to distinguish between A2 and B1. Moreover, the possibility could not be excluded that the RA33 preparation used for sequencing was a mixture of RA 33 and A2/B1. In other words, RA33 and A2/B1 could have been copurifying proteins migrating in SDS-PAGE as a single band. Therefore, it was necessary to demonstrate that RA33 was present in the hnRNP complex and exhibited the same properties as either A 2 or B1.

As most proteins of the hnRNP complex bind with intermediate or high affinity to RNA or ssDNA $(16,25)$, binding of
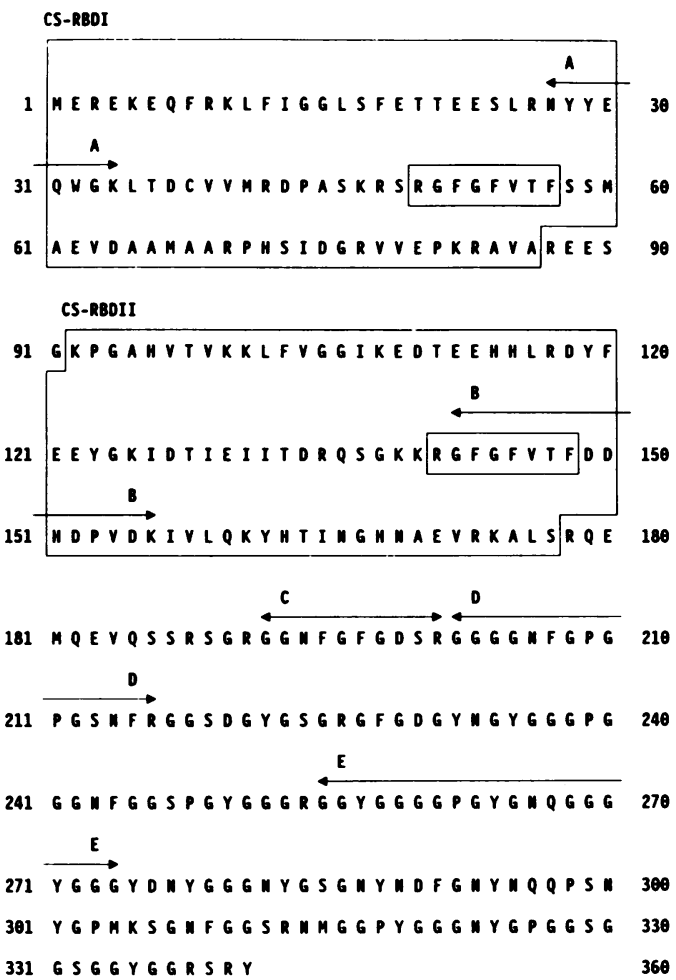

Figure 3. Primary structure of A2 hnRNP (21) in the one letter amino acid code. The conserved RNA binding domains (CS-RBD I and II) are indicated. The small boxes within these domains show the highly conserved octapeptides. The sequences of the five tryptic peptides $(A-E)$ derived from the purified RA33 preparation are indicated by arrows.

RA33 to ssDNA was investigated by fractionating a nuclear extract on ssDNA agarose as described in Methods. Bound proteins were eluted by gradually increasing the $\mathrm{NaCl}$ concentration from 0.1 to $2 \mathrm{M}$ (Fig. $4 \mathrm{~A}$ ). With the exception of the $\mathrm{C}$ proteins, the hnRNP proteins are known to coelute from ssDNA agarose between 0.3 and $0.5 \mathrm{M} \mathrm{NaCl}$ (16). Most of the proteins were collected in the flow-through of the column $(0.1$ $\mathrm{M} \mathrm{NaCl}$ ), and several weakly stained bands can be seen in the 0.2 and $0.3 \mathrm{M} \mathrm{NaCl}$ eluates. In the $0.5 \mathrm{M}$ fraction, however, a dominant double band and a faint doublet slightly above are clearly visible in the $30-40 \mathrm{kD}$ region: this pattern of doublet bands is similar to the characteristic pattern described for the A and $B$ proteins which in oligomeric hnRNP complexes are present in the molar ratio $3 \mathrm{~A} 1-3 \mathrm{~A} 2-1 \mathrm{~B} 1-1 \mathrm{~B} 2(17,26)$. The lower band of the dominant doublet was identified to be $\mathrm{A} 1$ by the $\mathrm{A} 1$ specific monoclonal antibody 4B10 (16) (not shown) and an A1 specific patient serum (Fig. $4 B$, lanes $B$ ). The upper band corresponding in size to A2 was immunostained by an RA33 specific serum (Fig. $4 B$, lanes $A$ ). This serum also stained the two minor bands above that most probably contained the $\mathrm{B}$ proteins. Interestingly, only trace amounts of other proteins were present in this fraction, whereas the $2 \mathrm{M}$ eluate contained at least 20 different proteins.

In a second experiment, $40 \mathrm{~S}$ hnRNP particles were isolated from a nuclear extract by sucrose gradient centrifugation. This procedure yielded a preparation of highly enriched hnRNP core proteins $(17,26)$. Subsequently, the presence of RA33 was detected using the RA33 reference serum, which predominantly stained a band in the mol wt region of the A proteins 

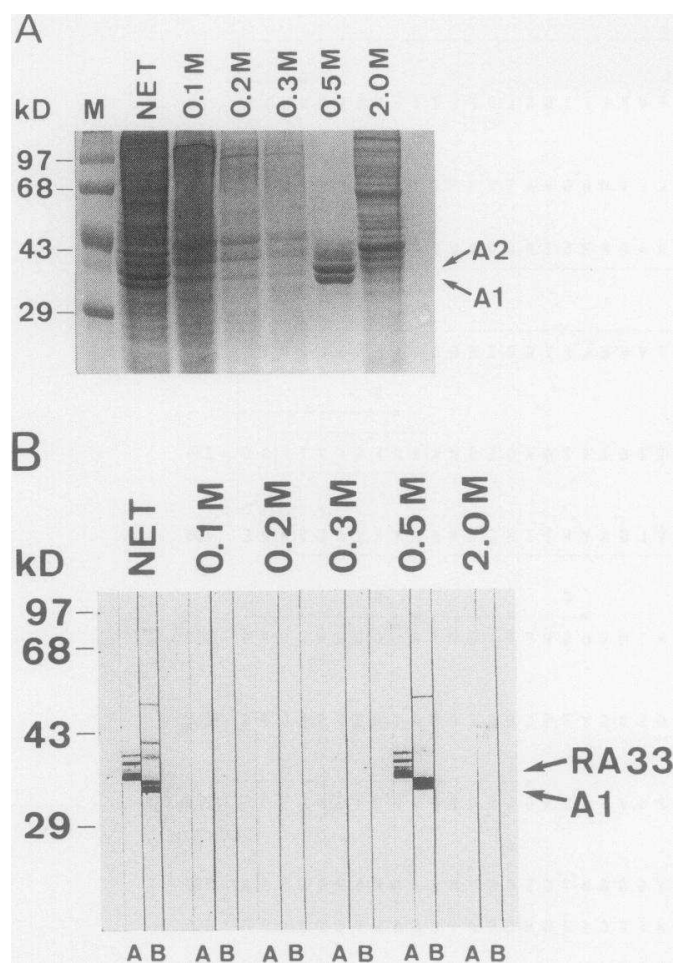

Figure 4. ssDNA chromatography of a low salt HeLa cell nuclear extract $(N E T)$. Proteins eluting at the $\mathrm{NaCl}$ concentrations indicated were analyzed by SDS-PAGE followed by Coomassie blue staining $(A)$ or immunoblotting $(B)$. The immunoblot was probed with the RA33 specific serum (lanes $A$ ) and with an Al hnRNP specific patient serum (lanes $B$ ). The positions of the hnRNP proteins $A 1$ and $A 2$ in panel $A$, and of the autoantigens A1 (visible as double band; see also 17,27$)$ and RA33 in $(B)$ are indicated by arrows.

(Fig. 5). The position of this band on the blot was indistinguishable from that of partially purified RA33, which was run in parallel on the same gel (Fig. 5, lane $H-S$ ). The staining of this band was most pronounced in fractions sedimenting in the 30S-40S range (fractions 6-8), and could not be observed in fractions sedimenting below $30 \mathrm{~S}$ (fractions 9-17). This band was not stained by the Al specific serum which reacted with a protein of slightly lower molecular mass (not shown).

Thus, it was demonstrated by independent experimental approaches that RA33 was indistinguishable from the hnRNP core protein A2. The two immunoreactive proteins copurifying with RA33 in ssDNA chromatography could not be identified unambigously. However, their migration relative to A1 and A2 on SDS gels appeared similar to that reported for the B1 and B2 proteins of the hnRNP particle.

Frequency and diagnostic specificity of anti-RA33 (antiA2). Purified RA33 was used as antigenic source on Western blots to show that the antigenic properties of the purified material were comparable to that contained in crude nuclear extracts. 15 RA33 positive sera were retested and found to be reactive also with highly purified RA33 (not shown). In addition, a total number of 120 sera from patients with RA, SLE, mixed connective tissue disease (MCTD), Sjögren's syndrome, polymyositis, scleroderma, reactive arthritis, osteoarthritis, and from healthy controls were investigated using a RA33 preparation partially purified by heparin-Sepharose chromatography (Table I). Taken together, antibodies to semipuri-

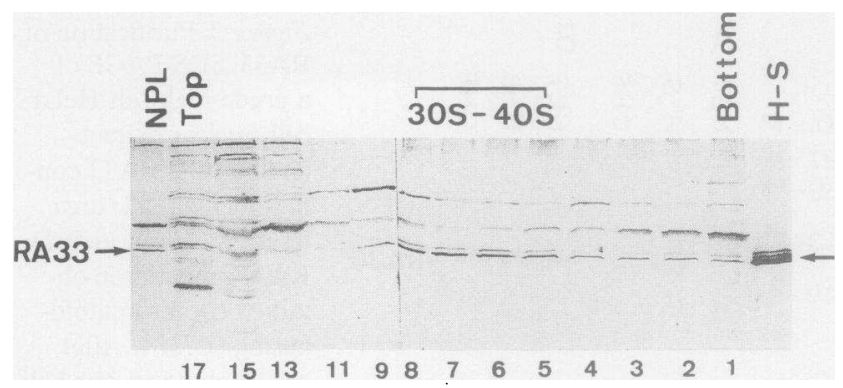

Figure 5. Analysis of the 40S hnRNP complex by immunoblotting. Fractions derived from sucrose gradient sedimentation of HeLa cell nucleoplasm $(N P L)$ were analyzed by immunoblotting for the presence of RA33. Top, bottom, and the position of the 30S-40S region of the gradient are indicated. Gradient fractions $1-8$ were electrophoresed separately, fractions $9 / 10,11 / 12,13 / 14,15 / 16$ and $17 / 18$ were combined. $H-S$ designates the partially purified RA33 preparation obtained by Heparin-Sepharose chromatography which was used as positive control. Arrows indicate the position of RA33 in the NPL and the $H-S$ lane.

fied RA33 (i.e., A2 hnRNP) were detected in 10 of 30 RA patients, in 4 of 10 MCTD patients, in 2 of 10 SLE patients, and in none of the other patients suffering from various inflammatory and degenerative rheumatic diseases, and in none of the controls.

\section{Discussion}

The data presented here reveal that the previously described nuclear autoantigen RA33 is indistinguishable from the A2 hnRNP protein, one of the six core proteins of the hnRNP complex $(17,19,21)$. Evidence for this is based on the following observations: ( $a$ ) the amino acid sequences of five tryptic peptides obtained from a highly purified RA33 preparation can be found in that of the A2 protein; $(b)$ the chromatographic behavior of RA33 was indistinguishable from A2 in ssDNA affinity chromatography; (c) RA33 was contained in the 40S hnRNP particle isolated by sucrose gradient centrifugation; and $(d)$ the molecular masses (estimated from SDS-PAGE) reported for RA33 and $\mathrm{A} 2$ are very similar, namely $33 \mathrm{kD}$ for RA33 (6) and 32.5-36 kD for A2 $(16,17,21,27)$. The sequencing data are also compatible with RA33 being the hnRNP core protein $B 1$ which is identical to A2 except for a 12-amino acid insertion near the $\mathrm{NH}_{2}$ terminus (21). How-

Table I. Frequency of Autoantibodies to Purified RA33 (A2 hnRNP) in Inflammatory and Degenerative Rheumatic Diseases

\begin{tabular}{lccc}
\multicolumn{1}{c}{ Patients } & $n$ & Positive sera & $\%$ \\
\hline RA & 30 & 10 & $33 \%$ \\
SLE & 10 & 2 & $20 \%$ \\
MCTD & 10 & 4 & $40 \%$ \\
Sjögren's syndrome & 5 & 0 & \\
Polymyositis & 5 & 0 & \\
Scleroderma & 5 & 0 & \\
Reactive arthritis & 20 & 0 & \\
Osteoarthritis & 15 & 0 & \\
Healthy controls & 20 & 0 &
\end{tabular}


ever, experimental evidence suggests that B1 corresponds to the relatively faint $36 \mathrm{kD}$ band that copurified with RA33 in chromatofocusing (Fig. 2): The estimated molecular mass of this protein is similar to that reported for $\mathrm{B} 1$, which ranges between 35.5 and $38 \mathrm{kD}(16,17,21,27)$. Next, the staining of the RA33 band and the 36-37 kD doublet (Fig. 2, lane $H-S$ ) indicated that RA33 was present in severalfold excess over these two proteins. This is compatible with the assumed molar ratio of 3:1 for A2 to B1 (and B2) in the hnRNP complex (26). Finally, when the A/B core proteins were isolated by ssDNA chromatography (a method that can be used for partial purification of hnRNP proteins [16]), the RA33 serum reacted with three antigens corresponding in size to $\mathrm{A} 2, \mathrm{~B} 1$ and $\mathrm{B} 2$. These antigens were apparently identical to the three antigens copurifying in heparin-Sepharose chromatography and (partially) in chromatofocusing. This interpretation is also compatible with the reported immuncrossreactivity of anti-A2 to B1 and B2: mouse antibodies affinity-purified from recombinant A2 bound not only to A2 but also to both B proteins (21). Given the high degree of sequence homology between A2 and B1, reactivity of both proteins with the same (auto) antibody would not be surprising. In fact, most RA33 positive sera have been found to be reactive also with the 36- and $37-\mathrm{kD}$ antigens assumed to be B1 and B2 (28, 29, unpublished observation). In this context, it should also be mentioned that monoclonal antibodies raised against hnRNP proteins frequently recognize several different proteins $(13,30)$.

When the A/B proteins were isolated by ssDNA chromatography anti-RA33 antibodies clearly reacted with the $\mathrm{A} 2$ band (and also with both the B1 and B2 band), but not with the A1 band. This was important to demonstrate since (recombinant) Al has already been identified as an autoantigen in a variety of connective tissue diseases (14). Even though A1 and A2 are related proteins sharing extensive sequence homologies in their $\mathrm{NH}_{2}$-terminal portions (21), anti-RA33 (A2) positive sera reacted only very infrequently with $\mathrm{A} 1$ (unpublished observation ). Since, however, their $\mathrm{COOH}$-terminal parts are only distantly related one could speculate that the $\mathrm{COOH}$-terminal part of A2 contains the epitope(s) eliciting A2 specific immune responses.

So far, hnRNPs have been studied only occasionally as target structures for autoantibodies $(11,12)$. In a study by Gelpi et al. (13), antibodies against hnRNPs were detected with high frequency in anti-U1RNP positive sera. As these sera reacted with one or more of the hnRNP proteins no preferential targets for the reacting autoantibodies could be identified. More recently, antibodies to recombinant Al hnRNP were described in patients with various connective tissue diseases (14). In contrast, a high disease specifity has been described for RA33 as antibodies against this protein were found almost exclusively in RA patients (6). This high specificity was not fully maintained when purified RA33 (i.e., A2, was used as antigen in immunoblotting since anti-RA33 antibodies were also detected in 4 of 10 sera from patients with MCTD and in 2 of 10 SLE sera [Table 1]). Interestingly, these 6 sera contained antibodies to U1snRNP in addition to anti-RA33; this could indicate the existence of crossreacting epitopes. The diagnostic value of anti-RA33 (anti-A2) is not severely impaired by this result since RA sera neither contain antibodies to UlsnRNP nor other specificities typically found in SLE sera (anti-DNA, antiSm, anti-Ro, anti-La ). Nevertheless, the clinical significance of anti-RA33 in MCTD and SLE, as well as the possible crossreactivity of anti-RA33 and U1snRNP, remains to be determined and will be the subject of future studies. Most importantly, all sera from patients with reactive arthritis and osteoarthritis were found negative for anti-RA33. Thus, this autoantibody is extremely useful to serologically differentiate RA from other arthritic diseases, which is often difficult, especially in the early stages of these diseases.

Although the detailed function of the hnRNP core proteins is not fully understood, they are known to closely interact with heterogeneous nuclear RNA $(17,31,32)$. At least the C proteins of the hnRNP complex have been shown to be involved in processing of pre-mRNA, thus demonstrating a functional and topographic link between hnRNPs and snRNPs (24, 33-36). Since monoclonal antibodies against $\mathrm{A} 2$ are not yet available purified, human autoantibodies could be used as scientific tools to further investigate structure and function of the hnRNP complex.

In summary, we have demonstrated that RA33 is indistinguishable from the A2 hnRNP protein, thereby identifying another ribonucleoprotein as an important autoantigen in rheumatic diseases. Subsequent studies using deletion mutants of recombinant A2 and linear peptides will elucidate the immunologically relevant regions of this important autoantigen. This could give additional insights into the pathogenetic mechanisms of rheumatoid arthritis and thus deepen our understanding of this autoimmune disorder.

\section{Acknowledgments}

The authors wish to thank Dr. G. Dreyfuss for providing the monoclonal antibody 4B10, H. Zellhofer for his expert technical assistance, Dr. T. R. Skern for critical reading of the manuscript, and Dr. W. van Venrooij for his encouraging and helpful comments.

This work was supported by research funds from the Fonds zur Förderung der Wissenschaftlichen Forschung, Vermächtnis der Josefine Hirtl zur Förderung der Medizinischen Forschung, and the Medizinisch Wissenschaftlicher Fonds des Bürgermeisters der Stadt Wien.

\section{References}

1. Harris, E. D. 1990. Rheumatoid arthritis: pathophysiology and implications for therapy. N. Engl. J. Med. 322:1277-1289.

2. Carson, D. 1989. Rheumatoid factor. In Textbook of Rheumatology. W. N. Kelley, E. D. Harris, S. Ruddy, and C. B. Sledge, editors. W. B. Saunders Company, Philadelphia 198-207.

3. Hannestad, K., and B. D. Stoller. 1978. Certain rheumatoid factors react with nucleosomes. Nature (Lond.). 275:671-673.

4. Alspaugh, M. A., G. Henle, E. T. Lennette, and W. Henle. 1981. Elevated levels of antibodies to Epstein-Barr virus in sera and synovial fluids from patients with rheumatoid arthritis. J. Clin. Invest. 67:1134-1140.

5. Venables, P. 1988. Epstein-Barr virus infection and autoimmunity in rheumatoid arthritis. Ann. Rheum. Dis. 47:265-269.

6. Hassfeld, W., G. Steiner, K. Hartmuth, G. Kolarz, O. Scherak, W. Graninger, N. Thumb, and J. S. Smolen. 1989. Demonstration of a new antinuclear antibody (anti-RA33) that is highly specific for rheumatoid arthritis. Arthritis Rheum. 32:1515-1520.

7. Tan, E. M., E. K. L. Chan, K. F. Sullivan, and R. L. Rubin. 1988. Antinuclear antibodies (ANAs): diagnostically specific immune markers and clues towards the understanding of systemic autoimmunity. Clin. Immunol. Immunopathol. 47:121-141.

8. Maniatis, T., and R. Reed. 1987. The role of small nuclear ribonucleoprotein particles in pre-mRNA splicing. Nature (Lond.). 325:673-678.

9. Lerner M. R., and J. A. Steitz. 1979. Antibodies to small nuclear RNAs complexed with proteins are produced by patients with systemic lupus erythematosus. Proc. Natl. Acad. Sci. USA. 76:5495-5499.

10. van Venrooij, W. J., and P. T. G. Sillekens. 1989. Small nuclear RNA associated proteins: autoantigens in connective tissue diseases. Clin. Exp. Rheumatol. 7:635-645.

11. Habets, W. J., D. J. de Rooij, M. H. Salden, A. P. Verhagen, C. A. van Eekelen, L. B. van den Putte, and W. J. van Venrooij. 1983. Antibodies against 
distinct nuclear matrix proteins are characteristic for mixed connective tissue disease. Clin. Exp. Immunol. 54:265-276.

12. Frizler, M. J., R. Ali, and E. M. Tan. 1984. Antibodies from patients with mixed connective tissue disease react with heterogeneous nuclear ribonucleoprotein or ribonucleic acid of the nuclear matrix. J. Immunol. 132:1216-1222.

13. Gelpi, C., J. L. Rodriquez-Sanchez, and J. A. Hardin. 1988. Purification of hnRNP from HeLa cells with a monoclonal antibody and its application in ELISA: detection of autoantibodies. Clin. Exp. Immunol. 71:281-288.

14. Astaldi-Ricotti, G. C. B., M. Bastagno, A. Cerini, C. Negri, R. Caporali, F. Cobianchi, M. Longhi, and C. Montecucco. 1989. Antibodies to hnRNP core protein A1 in connective tissue diseases. J. Cell. Biochem. 40:1-5.

15. Montecucco, C., R. Caporali, C. Negri, F. deGennaro, A. Cerino, M. Bestagno, F. Cobianchi, and G. Astaldi-Ricotti. 1990. Antibodies from patients with rheumatoid arthritis and systemic lupus erythematosus recognize different epitopes of a single heterogeneous nuclear RNP core protein. Arthritis Rheum. 33:180-186.

16. Piñol-Roma, S., Y. D. Choi, M. J. Matunis, and G. Dreyfuss. 1988. Immunopurification of heterogeneous nuclear ribonucleoprotein particles reveals an assortment of RNA-binding proteins. Genes \& Dev. 2:215-227.

17. Beyer, A. L., M. E. Christensen, B. W. Walker, and W. M. LeStourgeon. 1977. Identification and characterization of the packaging proteins of core $40 \mathrm{~S}$ hnRNP particles. Cell. 11:127-138.

18. Cobianchi, F., D. N. SenGupta, B. Z. Zmudzka, and S. H. Wilson. 1986. Structure of rodent helix-destabilizing protein revealed by cDNA cloning. J. Biol. Chem. 261:3536-3543.

19. Kumar, A., K. R. Williams, and W. Szer. 1986. Purification and domain structure of core hnRNP proteins A1 and A2 and their relationship to singlestranded DNA-binding proteins. J. Biol. Chem. 261:11266-11273.

20. Swanson, M. S., T. Y. Nakagawa, K. LeVan, and G. Dreyfuss. 1987. Primary structure of human nuclear ribonucleoprotein particle $C$ proteins: conservation of sequence and domain structures in heterogeneous nuclear RNA, mRNA and pre-rRNA binding proteins. Mol. Cell. Biol. 7:1731-1739.

21. Burd, C. G., M. S. Swanson, M. Görlach, and G. Dreyfuss. 1989. Primary structures of the heterogeneous nuclear ribonucleoprotein A2, B1, and C2 proteins: A diversity of RNA binding proteins is generated by small peptide inserts. Proc. Natl. Acad. Sci. USA. 86:9788-9792.

22. Buvoli, M., F. Cobianchi, M. G. Bestagno, A. Mangiarotti, M. T. Bassi, G. Biamonti, and S. Riva. 1990. Alternative splicing in the human gene for the core protein Al generates another hnRNP protein. EMBO J. (Eur. Mol. Biol. Organ.) 9:1229-1235
23. Bandziulis, R. J., M. S. Swanson, and G. Dreyfuss. 1989. RNA-binding proteins as developmental regulators. Genes Dev. 3:431-437.

24. Choi, Y. D., P. J. Grabowski, P. A. Sharp, and G. Dreyfuss. 1986. Heterogeneous nuclear ribonucleoproteins: Role in RNA splicing. Science (Wash. DC). 231:1534-1539.

25. Swanson, M. S., and G. Dreyfuss. 1988. Classification and purification of heterogeneous ribonucleoprotein particles by RNA-binding specificities. Mol. Cell. Biol. 8:2237-2241.

26. Barnett, S. F., S. J. Northington, and W. M. LeSturgeon. 1990. Isolation and in vitro assembly of nuclear ribonucleoprotein particles and purification of core protein particles. Methods Enzymol. 181:293-307.

27. Wilk, H. E., H. Werr, D. Friedrich, H. H. Kiltz, and K. P. Schaefer. 1985. The core proteins of $35 \mathrm{~S}$ hnRNP complex: characterization of nine different species. Eur. J. Biochem. 146:71-81.

28. Steiner, G., W. Hassfeld, O. Sinski, and J. Smolen. 1990. Purification of RA33 and related antigens. Clin. Rheumatol. 9:576. (Abstr.)

29. Hassfeld, W., G. Steiner, and J. S. Smolen. 1990. Letter. N. Engl. J. Med. 323:995-996

30. Leser, G.P., J. Escara-Wilke, and T.E. Martin. 1984. Monoclonal antibodies to heterogeneous nuclear RNA-protein complexes. J. Biol. Chem. 259:18271833.

31. Economidis I. V., and T. Pederson. 1983. Structure of nuclear ribonucleoprotein: heterogeneous nuclear RNA is complexed with a major sextet of proteins in vivo. Proc. Natl. Acad. Sci. USA. 80:1599-1602.

32. Choi, Y. D., and G. Dreyfuss. 1984. Isolation of the heterogeneous nuclear RNA-ribonucleoprotein complex (hnRNP): a unique supramolecular assembly. Proc. Natl. Acad. Sci. USA. 81:7471-7475.

33. Sierakowska, H., W. Szer, P. J. Furdon, and R. Kole. 1986. Antibodies to hnRNP core proteins inhibit in vitro splicing of human $\beta$-globin mRNA. Nucleic Acids Res. 14:5241-5254.

34. Swanson, M. S., and G. Dreyfuss. 1988. RNA binding specificity of hnRNP proteins: a subset binds to the 3 ' end of introns. EMBO (Eur. Mol. Biol. Organ.) J. 11:3519-3529.

35. Buvoli M., F. Cobianchi, G. Biamonti, and S. Riva. 1990. Recombinant hnRNP protein A1 and its N-terminal domain show preferential affinity for oligodeoxynucleotides homologous to intron/exon acceptor sites. Nucleic Acids Res. 18:6595-6600.

36. Mayrand, S. H., and T. Pedersen. 1990. Crosslinking of hnRNP proteins to pre-mRNA requires U1 and U2 snRNPs. Nucleic Acids Res. 18:3307-3318. 